\title{
Modern Manufacturing Processes: A Review
}

\author{
Velayudham A \\ Scientist 'E', Combat Vehicles Research and Development Establishment, \\ Avadi, Chennai, India
}

\begin{abstract}
Necessity to use new materials, demanding functional requirements and miniaturization have led to evolution of modern manufacturing processes. Developments are taking place both in the conventional methods and unconventional methods of manufacture. High speed machining, hard machining, non conventional processes like beam, mechanical and chemical processes and additive processes like rapid prototyping are some of the modern manufacturing processes. This paper aims to give overview of modern manufacturing processes that are currently under use/research in the manufacturing arena.
\end{abstract}

Key words: High Speed Machining, Machining, Grinding, Micro Electro Chemical Machining, Forming, Turning, Sintering

\section{INTRODUCTION}

Currently, manufacturing companies have to compete in a more and more global market. This global competition has resulted in the development of new materials, processes and products. The most important aspect of these is the advanced design and manufacturing concepts involved in their production. The necessity to use newer materials for different applications and control of their dimensional accuracies has led to evolution of modern manufacturing methods or processes. This paper reviews some of the modern manufacturing methods which are used currently / under research and their applications. This would help in deciding whether these processes are a viable alternative to what are currently under practice.

\section{MANUFACTURING PROCESSES}

Manufacturing transforms bulk material into finished products. This process of transformation can be done by putting material together, by moving material from one region to another and subtracting unwanted material [1]. Advancements are taking place in each of the methods. Of the above methods conventional processes are being followed to process the materials that are within some level of hardness condition. To process materials with beyond certain level of workable condition, new processes with unconventional approach are followed. The advancements in each of these will be discussed one by one.

\section{A. Advances in Conventional Machining Processes High Speed Machining}

Developments in ultra-hard cutting tool materials, together with improved machine tool spindle and drive systems, have led to the ability to machine at much higher cutting speeds than previously possible. High speed machining (HSM) allows high material removal rates while maintaining relatively low feeds. Thus chip loads and cutting forces can be moderately low. This enables complex shapes to be economically machined from the solid, including items with very thin sections. The high speed machining is defined as being where conventional cutting speeds of a particular material are exceeded by a factor of 5-10 (Fig.1). Increased machining accuracy, particularly when machining thin webs, etc., due to reduced chip loads, improved surface finish are some of the advantages of HSM [2]. A limitation of using HSM for the more difficult to machine materials can be reduced tool life and hence the overall cost of machining must be considered.

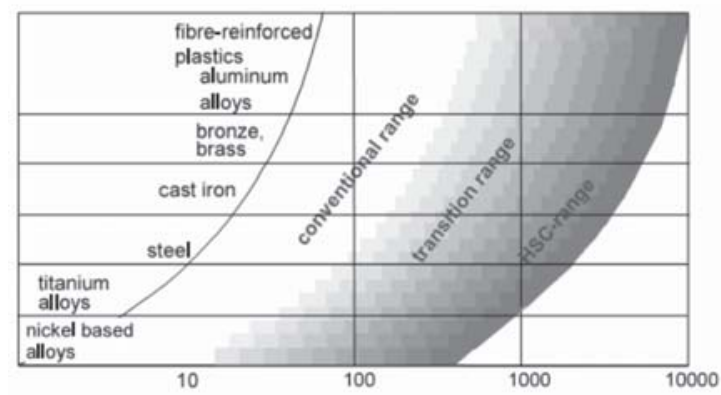

Fig.1. Cutting Speed Area Depends On Material ${ }^{3}$

\section{B. Hard Machining}

Hard machining is a machining process carried out on ${ }^{\circ}$ hard ${ }^{\circ}$ materials (where ${ }^{\circ}$ hard ${ }^{\circ}$ is defined as having hardness greater than $45 \mathrm{Rc}$ ). The process is intended to replace or limit traditional grinding operations that are expensive, environmentally unfriendly, and inflexible. The 
usual manufacturing sequence for a hardened steel shaft, for example, would be rough turning, finish turning, and hardening followed by finish grinding. With the development of modem hard tool materials (Ceramics and $\mathrm{CBN}$ ), an alternative manufacturing process is turning of the material in its hardened state (hard turning or hard machining). Due to its increased flexibility, it is a competitive alternative to finish grinding. Material removal rates are much higher than grinding and thus machining times can be substantially reduced. There is a reduction in the number of separate machines required with associated reductions in lost production time from setups and transfer between workstations [4].

\section{DUCTILE REGIME MACHINING}

Improvements in machining tolerances have enabled researchers to expose the ductile material removal of brittle materials. Under certain controlled conditions, it is possible to machine brittle materials like ceramics using single point diamond tools so that material is removed by plastic deformation, leaving a crack-free surface. This process is termed as "ductile regime machining". Ductile regime machining follows from the fact that all materials will deform plastically if the scale of deformation is very small [5].

\section{A. Peel Grinding}

Peel grinding is one of the latest techniques used for machining hard materials. It uses a narrow grinding wheel, usually $6.4 \mathrm{~mm}$ or less in width, to grind a part. Because this process is like machining with a conventional lathe, it is a major competitor to hard turning. The thin wheel functions like a single point tool under CNC control. Therefore it is simple to change profiles without changing wheels. It is also suited to grind dissimilar materials on one platform. Flexibility is one of the main attractions of peel grinding and another key advantage is that there are no driver dogs. But to be successful, machine tools should have high static and dynamic stiffness [6].

\section{B. Hybrid Approaches In Conventional Processes Laser Assisted Machining (lam)}

Laser assisted machining is a new and innovative way of machining hard to wear materials, which are difficult to machine using conventional methods. LAM combines laser technology with traditional machining methods such as a turning and milling. The laser is used as a heat source with beam focused on the unmachined section of the workpiece directly in front of the cutting tool [7]. The addition of heat softens the surface layer of the material, so that ductile deformation rather than brittle deformation occurs during cutting. By focusing a laser beam on to the surface of the material, it locally heats the material to more than $1,000 \mathrm{öC}$ making it softer and more ductile. The soft, red-hot material (e.g., Ceramic) is then removed with a cutting tool made out of ultra-hard diamond-like material called cubic boron nitride.

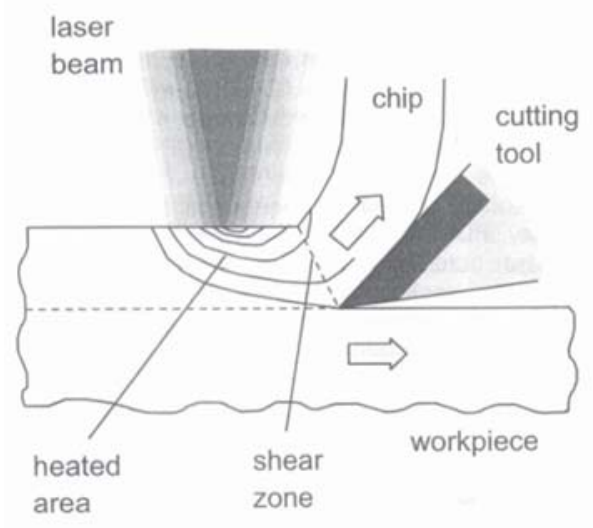

Fig.2. Laser Assisted Machining

But the position and strength of the laser must be controlled precisely so that it heats only a tiny portion of material just before it is machined and does not damage the work surface and tool.

\section{Deformation Machining}

Deformation machining is a novel hybrid process that, on one machine, and in one step, combines the machining of thin structures and single point incremental forming. Starting from plate stock, thin features (walls, floors, or even pins) are created by machining operations. Then using a forming tool single point incremental forming is used to create deformations of thin sections in two different ways, by bending the features or by stretching. Fig. 3 illustrates deformation machining with bending mode. By switching

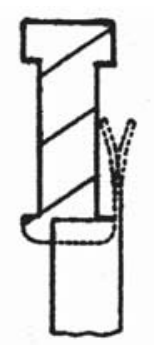

(a)

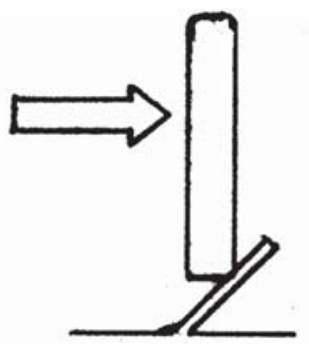

(b)
Fig. 3. Deformation Machining (a), Machining and (b) Deforming 
between the cutting tool and the deformation tool, this hybrid combination allows making interesting features which are thinner, lighter or less expensive than the structures they replace, and which have novel geometries that were previously not possible [8].

\section{Advances in Unconventional Manufacturing Processes}

Emergence of advanced engineering materials, stringent design requirements, intricate shape and unusual size of workpiece (miniaturization) restrict the use of conventional machining methods. Hence, it was realized to develop appropriate unconventional manufacturing approaches. These processes are classified according to the source of energy used to generate such machining action: mechanical, thermal, chemical and electrochemical. Of these methods, some the widely used methods of manufacturing are discussed in the following paragraphs with respect to their principle, applications and advancements.

\section{MECHANICAL METHODS OF UNCONVENTIONAL PROCESSES}

The principles of mechanical methods of unconventional manufacturing processes are illustrated in Fig. 4.

\section{A. Water Jet Machining (WJM)}

The key element in water jet machining is a water jet, which travels at velocities as high as $900 \mathrm{~m} / \mathrm{sec}$ (approximately Mach 3). When the stream strikes a workpiece surface, the erosive force of water removes the material rapidly. One of the most crucial elements is the nozzle, in which water pressure is transformed into high velocity water jet and thus need proper design. Water jet machining is applied in various industrial areas ranging from cleaning, deburring and cutting of titanium in aerospace industries. It is also widely used for the machining of fibre reinforced plastics.

\section{B. brasive Water Jet Machining (AWJM)}

Harder materials such as glass, ceramics, concrete and tough composites are cut by adding abrasives to the water jet during abrasive water jet machining. The addition of abrasives to the water jet enhances the material removal rate

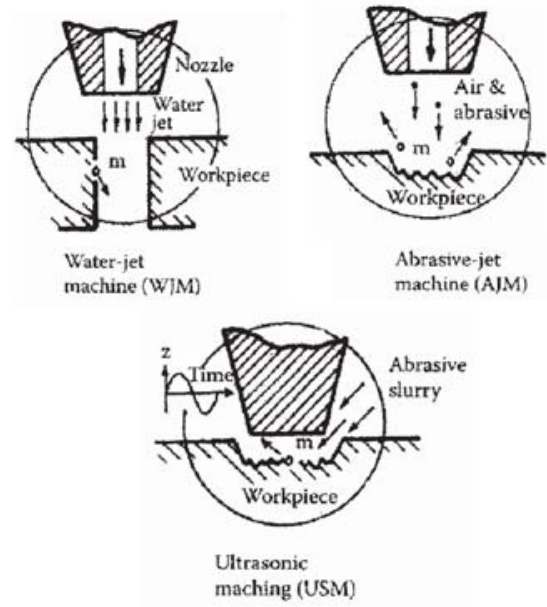

Fig.4. Mechanical Methods

and produces cutting speeds between 51 and 460 $\mathrm{mm} / \mathrm{min}$. It is claimed that the abrasive water jet is hundred times more powerful than the pure water [9]. It uses a low pressure of 4.2 bar to accelerate a large volume of water $(70 \%)$ and abrasive $(30 \%)$ mixture up to a velocity of 30 $\mathrm{m} / \mathrm{s}$. Silicon carbides, corundum and glass beads of grain size 10 to $150 \mu \mathrm{m}$ are often used as abrasive materials. AWJM cuts through $350 \mathrm{~mm}$ thick slabs of concrete or $75 \mathrm{~mm}$ thick of tool steel plates at $38 \mathrm{~mm} / \mathrm{min}$ in a single pass. Abrasive water jet also has some limitations, which include; high noise levels, safety, low removal rates, inability to machine blind holes or pockets etc.

There are also other versions like magnetic field assisted abrasive finishing processes which are mostly applied for polishing of balls and rollers.

\section{C.Ultrasonic Machining}

Ultrasonic machining (UM) is the removal of hard and brittle materials using an axially oscillating tool at ultrasonic frequencies $(18-20 \mathrm{kHz})$. The tool that is vibrated at ultrasonic frequency drives the abrasive slurry which is usually composed of $50 \%$ (by volume) fine abrasive grains (100-800 grit number) of boron carbide $\left(\mathrm{B}_{4} \mathrm{C}\right)$, aluminum oxide $\left(\mathrm{Al}_{2} \mathrm{O}_{3}\right)$, or silicon carbide $(\mathrm{SiC})$ in $50 \%$ water, to create a brittle breakage on the workpiece surface [10]. The shape and dimensions of the workpiece depend on those of the tool. Since material removal is based on brittle breakage, this material is suitable for machining brittle materials such as glass, ceramics, silicon and graphite.

In ultrasonic machining typical form errors like overcut, conicity and out of roundness result due to side 
wear of the tool. Depends upon the grit number, the surface finish varies from 0.38 to $0.25 \mu \mathrm{m}$. The important applications are drilling and coring, sinking and contour machining, production of EDM electrode, polishing etc. The accuracy of machining can be enhanced by introducing additional features wherein it is called as micro-Ultrasonic machining. It is a method that utilizes workpiece vibration. According to Egashira and Masuzana [11], vibrating the workpiece allows for freer tool system design because it does not include the set of transducer, horn, and cone. In addition, the complete system is much more simple and compact than conventional USM. Using such a method, microholes of $5 \mu \mathrm{m}$ diameter on quartz, glass and silicon have been produced using tungsten carbide alloy microtools.

\section{THERMAL METHODS OF UNCONVENTIONAL PROCESSES}

The principles of thermal methods of unconventional manufacturing processes are illustrated in Fig. 5.

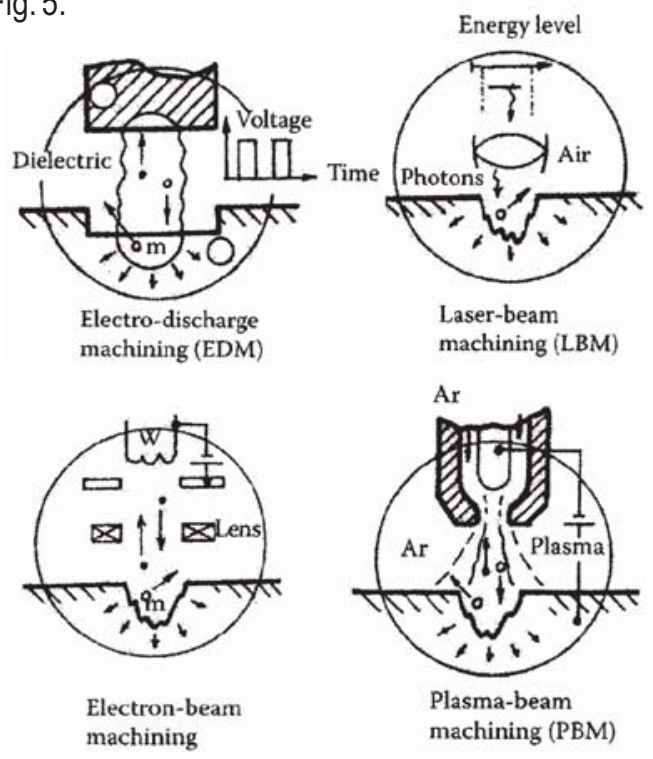

Fig.5. Thermal Methods

\section{A. Electrical Discharge Machining}

Electrical discharge machining involves a controlled erosion of electrically conductive materials by the initiation of rapid and repetitive spark discharge between the electrode tool (usually cathode) and workpiece (anode), separated by a small gap of about 0.01 to $0.50 \mathrm{~mm}$ known as the spark gap. This spark gap is either flooded or immersed under the dielectric fluid like hydrocarbon oil or de-ionized

(de-mineralized)

water. The dielectric fluid in the spark gap is ionized under the pulsed application of the direct current, thus enabling a spark discharge to pass between the electrodes. Each spark produces enough heat to melt and vaporize a tiny volume of the workpiece material, leaving a small crater on its surface. The process requires the workpiece material to be conductive and the hardness of the material is not critical.

Different versions of EDM exist: EDM die-sinking, wire EDM, EDM drilling, EDM milling and electro discharge grinding [12]. Non-circular holes are also produced by a planetary movement of tool with rotation. The use of EDM principle in conjunction with turning has been extended by Masuzawa [10].

\section{B. Micro EDM Process}

Micro EDM is employed in the field of micro-mould making and used for producing grooves and channels, bore holes, linear profiles and even complex formed 3D structures.

With appropriate parameters, it is possible for micro EDM process to achieve high precision and high quality machining. The non-contact nature of EDM makes it possible to use a very long and thin electrode for machining.

In conventional EDM, there exists only one discharge point for each pulse. On the other hand with the newly developed Multi-spark EDM method [13], two discharge points can be obtained for each pulse by the modified basic circuit. The removal rate and energy efficiency of Multi-spark EDM method are considerably higher. A schematic of wire electro-discharge grinding (WEDG) developed by Masuzawa et al. [14] is illustrated in Fig. 6. Using a wire electrode traveling along the groove of a wire guide, a micro rod can be machined like in a turning process.

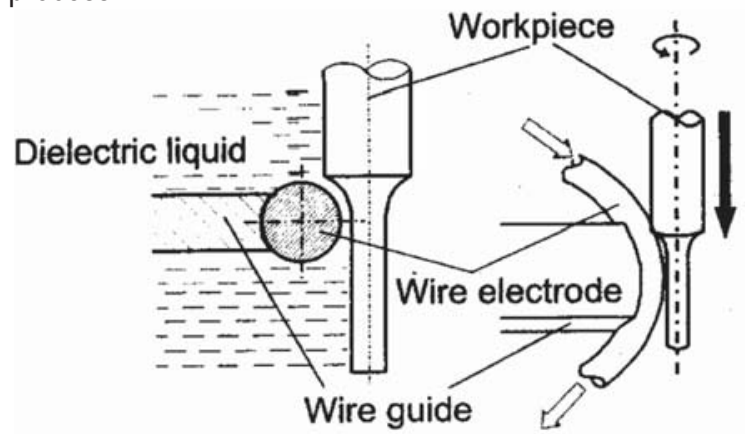

Fig.6. Wire Electro Discharge Grinding (WEDG) Method

EDM process can also be used as a surface treatment method and/or an additive process. As shown in Fig. 7, a hard material (TiC) layer is coated on the workpiece [15] surface, 


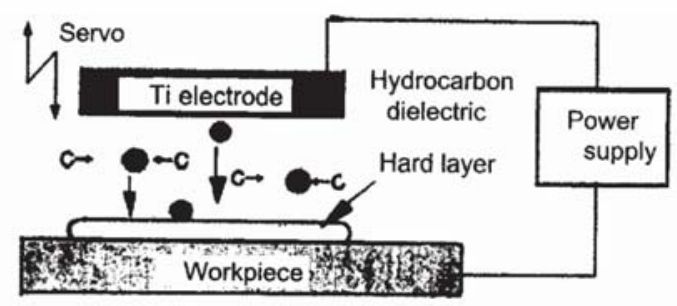

Fig.7. Principle of EDM Surface Modification

since $\mathrm{Ti}$ is carbonized in the hydrocarbon oil. Coloring titanium alloys using WEDM process is a new method. Methods are also developed to machine electrically nonconductive materials like diamond, ceramics by EDM through applying suitable conductive coating [16] as illustrated in Fig. 8. Dry EDM is an innovation in micro EDM.

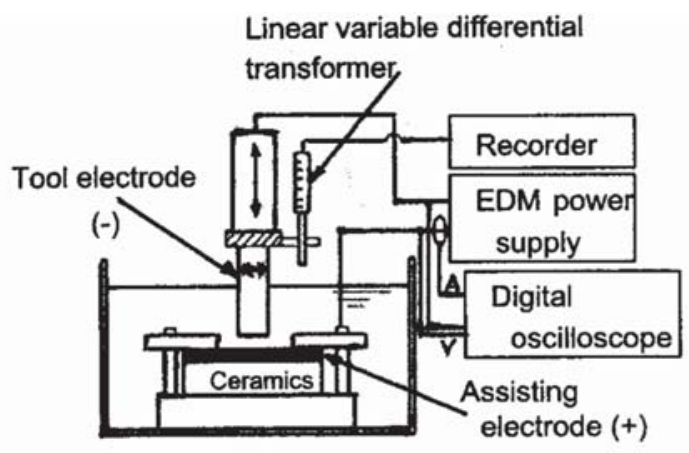

Fig.8. Schematic illustration of EDM for insulating ceramics with an assisting electrode method

\section{Laser Beam Machining (LBM)}

Laser beam machining is one of the most widely used thermal energy machining methods to process almost whole range of materials. Laser light differs from ordinary light because it has the photons of same frequency, wavelength and phase. Thus, unlike ordinary light laser beams are highly directional, have high power density and better focusing characteristics. Among different type of lasers, $\mathrm{Nd}: \mathrm{YAG}$ and $\mathrm{CO}_{2}$ are most widely used for LBM application. The mechanism of material removal during laser beam machining includes different stages such as melting, vaporization and chemical degradation. When a high energy density laser bream is focused on work surface, the thermal energy is absorbed which heats and transforms the work volume into a molten, vaporized or chemically changed state that can easily be removed by flow of high pressure assist gas jet[17].

\section{Micro Laser Beam Machining}

Micro LBM is an advanced process for micromachining applications, wherein the beam is focused to a small spot. With the development of Femto second laser and Excimer lasers, the applications extend to ablation, lithography, micro fabrication etc. When combined with a multi-axis workpiece positioning system or robot, the laser beam can be used for drilling, cutting, grooving, welding, and heat treating processes on a single machine [18]. Holes as small as $0.005 \mathrm{~mm}$ with an aspect ratio of 50 has been produced on thin sheets of about $0.025 \mathrm{~mm}$.

\section{E. Electron Beam Machining (EBM)}

In electron-beam machining, material is removed by means of a focused beam of high velocity electrons that strike the workpiece. Electrons are emitted from an electron gun and are accelerated to speeds of about $75 \%$ of the speed of light, by voltages as high as $50 \mathrm{kV}$ between the anode and cathode. A magnetic lens focuses the electron beam onto the workpiece, and energy densities of the order of $108 \mathrm{~W} / \mathrm{cm}^{2}$. The kinetic energy of the electrons is converted into heat that is sufficient to cause rapid melting and vaporization of the workpiece material [19]. To eliminate scattering of the beam of electrons, the work is done in a high-vacuum chamber.

Electron-beam machining can process a wide range of materials. As a result of extremely high energy density of the beam and the short duration of beam-workpiece interaction, thermal effects on the workpiece material are limited to a heat affected zone that seldom exceeds 0.025 $\mathrm{mm}$ in depth. The high beam-power density also enables high aspect ratio holes to be drilled, often as large as 15 to 1.

\section{F. PlasmaArc Machining (PAM)}

Plasma arc machining is predominantly used in metal fabrication and sheet metal industries. But by suitably altering arc passage, it can be used in surface modification processes like sprayed coating on composites, ceramics etc. A high temperature (200000̈ 3000000 ) plasma, a stream of glowing ionized gas is the energy source for PAM. Gases get into this fourth state of matter when they stream past an electric arc struck between a cathode and a positive nozzle (direct arc) or between a cathode and the workpiece (transferred arc). The plasma jet heats the workpiece by bombardment with electrons and by transfer of energy from high temperature, high energy gas. 


\section{G. Ion Beam Machining (IBM)}

lon beam machining (IBM) is generally classified among the thermoelectric processes along with electron beam, laser beam, plasma arc and electric discharge machining. Unlike most of these techniques, however, this process does not depend on heating of the material to the point of evaporation. Instead, it removes material by the sputtering of ions. This sputter etching mechanism is basically simple. A stream of ions bombards the surface of the target material. Each bombarding ion dislodges surface atoms by transferring kinetic energy from itself to the atoms. The effect is much the same as a billiard ball hitting massed groups of other billiard balls, except that in this case a certain amount of interatomic binding energy must be overcome. IBM machining is mostly applied in micro machining (etching) of electronic components like computer memories. It is also used for deposition of thin film of material, particularly in electronic industries.

\section{CHEMICAL METHODS OF UNCONVENTIONAL PROCESSES}

The principles of chemical methods of unconventional manufacturing processes are illustrated in Fig. 9.

\section{A. Electro Chemical Machining (ECM)}

Electrochemical machining is the controlled removal of metal by anodic dissolution in an electrolytic medium in which the workpiece is the anode and the tool is the cathode. Two electrodes are placed closely with a gap of about $0.5 \mathrm{~mm}$ and immersed in an electrolyte which is a solution of sodium chloride. When an electrical potential of about $20 \mathrm{~V}$ is applied between the electrodes, the ions existing in the electrolyte migrate towards the electrodes. Positively charged ions are attracted towards the cathode and the negatively charged ions are attracted towards the anode. This initiates the flow of current in the electrolyte. The rate at which the ions arrive at their respective electrode determines the density of current and varies in direct proportion to the applied voltage, the number of ions present and the gap between the electrodes. The electrolysis process that takes place at the cathode liberates hydroxyl ions (negatively charged) and free hydrogen. The hydroxyl ions combine with the metal ions of anode to form insoluble metal hydroxides and the material is thus removed from the anode. This process continues and the tool reproduces its shape in the workpiece (anode).

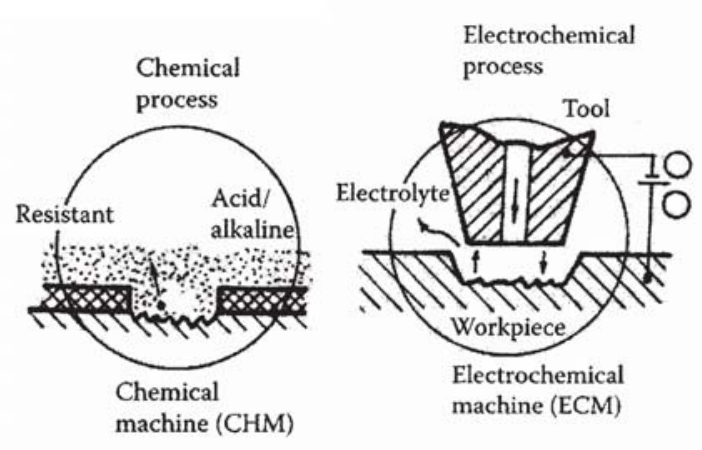

Fig.9. Chemical Methods

The main advantage of this process is production any complicate contoured shape with completely stress free surface. It has been applied in a wide variety of industrial applications ranging from cavity sinking to deburring. The ability to machine high strength and heat resistant materials has led to many cost saving applications where other processes are impractical. However the main drawback of ECM is low process and low accuracy machining process due to its wider machining gap. This draw back is removed in the case of micro ECM.

\section{B. Micro Electrochemical Machining}

As illustrated in Fig. 10, in micro ECM an electrolyte jet is used as a microtool [20]. Moving the workpiece and controlling or switching the pulse current produces small

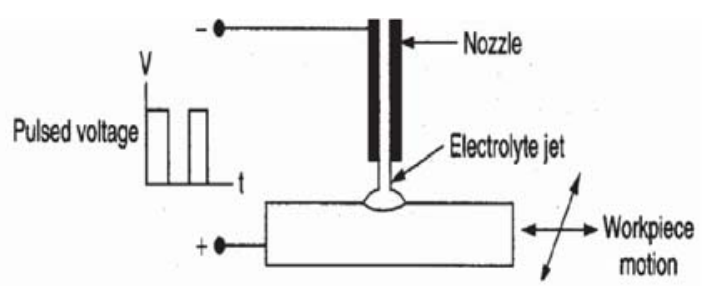

Fig. 10. Electrolyte Jet Micro ECM

indents or cavities in pre-designed alignment. Application of ECM in the processing of thin films and in the fabrication of microstructures referred to as electrochemical micromachining (EMM). Some of the applications of mask less and through-mask EMM in the fabrication of components are copper lines for PCBs, slider suspension for magnetic recording, cone connectors for pad-on-pad connector contacts, flip-chip interconnects and inkjet nozzle plates [21].

\section{Advances In Forming Methods}

Light weight construction is crucial where mass is critical to enable the product function like in aeronautical 
applications [22]. For such critical applications manufacturing process like forming is most widely used.

\section{Electroforming}

Electro forming is basically a specialized form of electroplating. In electroplating, metal is dissolved electrolytically at an anode [23]. The basic principle of electroforming is illustrated in Fig.11. The resulting metal ions are transported through an electrolyte solution, usually containing a high concentration of the same metallic ions, to be deposited at a cathode. Some of the applications of electroforming to manufacturing microstructures and microelectromechanical systems (MEMS) are LIGA, micromoulding and photoelectroforming.

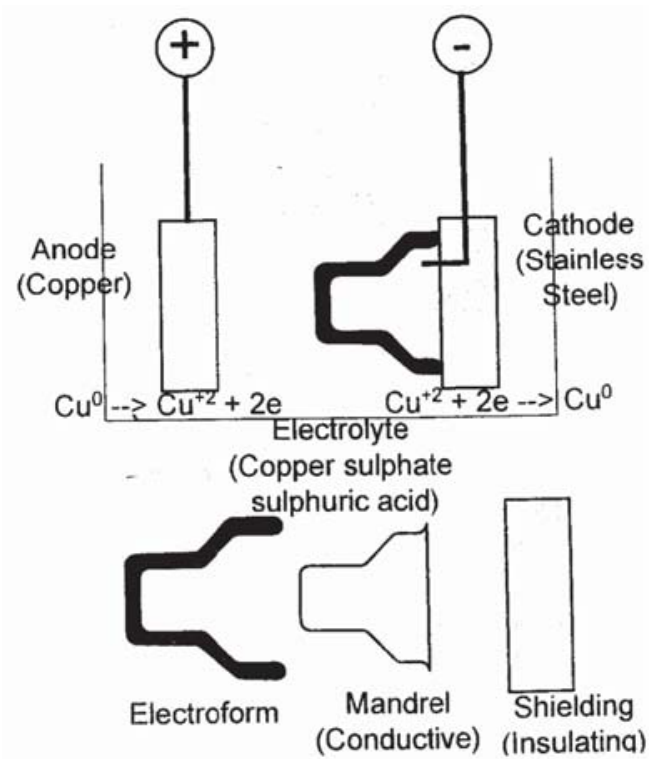

Fig. 11. Principle of Electroforming

\section{HYBRID APPROACHES IN UNCONVENTIONAL PROCESSES}

Currently technological improvement of machining processes are being taking place by combining different machining actions to make use of the combined advantages and to avoid or reduce some adverse effects the constituent processes produce when they are individually applied. Depending on the major machining phase involved in the material removal, hybrid machining can be classified into hybrid chemical and electrochemical processes and hybrid thermal machining [20].

In the hybrid chemical and electrochemical processes, the major material removal phase is either chemical dissolution or electrochemical dissolution. Such a machining action can be combined with the thermal assistance by local heating in case of laser-assisted electrochemical machining. In other words, the introduction of the mechanical abrasion action assists the electrochemical dissolution machining phase during electrochemical grinding and electrochemical super finishing. Ultrasonic-assisted electrochemical machining employs an USM component with ECM.

In the case of hybrid thermal machining, the main material removal mechanism is a thermal one. The combination of this phase with the ECD phase, mechanical abrasion action, and ultrasonic vibration generates a family of double action processes. The triplex hybrid machining is also achievable by combining the electrodischarge erosion phase, the ECD action, and the mechanical abrasion grinding. Some of the hybrid processes are illustrated in Fig. 12.

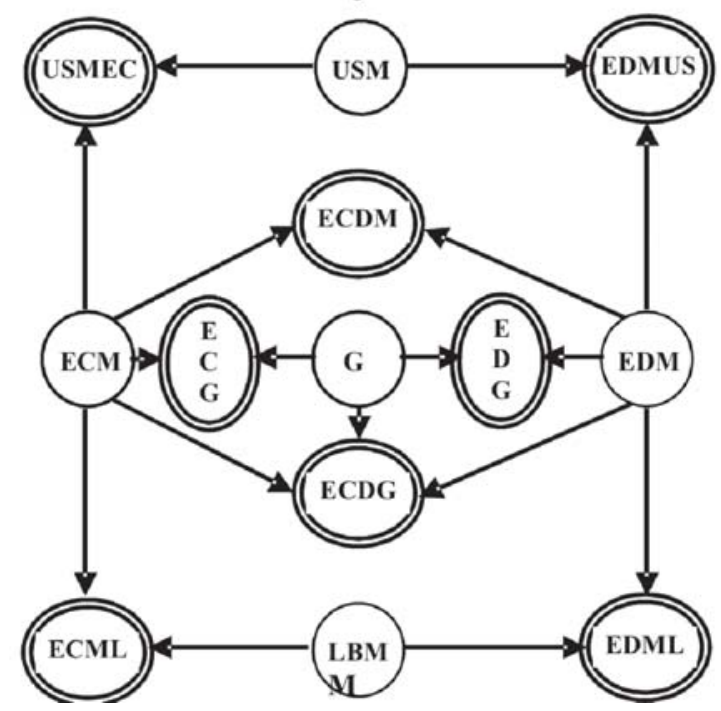

Fig. 12. Hybrid Machining Processes

\section{A. Micro EDM and Micro Turning Process}

Fig. 13 illustrates the concept of Turning-EDM hybrid machining. In this hybrid machining process, EDM is carried out using a micro-shaft [24]. An electrode of required length is fabricated using micro Turning process. Using this hybrid machining, clamping error can be avoided and deflection of electrode can be minimized, consequently the accuracy of machining can be improved. This hybrid machining technology can be used to fabricate a cylindrical micro- component with non-rotational portion such as a key slot or flat bar by the help of EDM process followed by turning. 

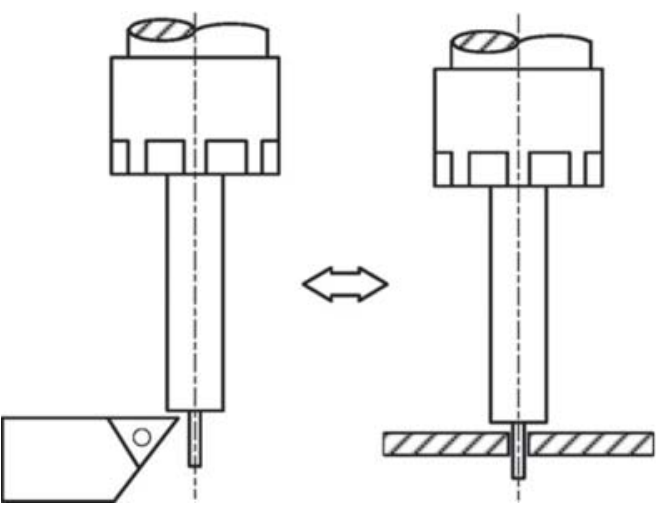

Fig. 13 Concept of hybrid micro-EDM processes

\section{B. Laser assisted Micro Forming}

The application of metal forming technologies to the production of metallic micro parts is limited by problems like influence of microstructure arising from size effects. An approach to these problems is the laser assistance of the micro forming process. Fig. 14 illustrates the principle of laser assisted micro forming. Laser light is used to increase the temperature of the material during forming, increasing the formability in the required area of the part and reducing the flow stress and anisotropy of the material [25]. The applications of micro forming are to the smallest dimensions (down to $100 \mu \mathrm{m}$ ) like miniature springs and screws, connector pins, shafts or gears [26].

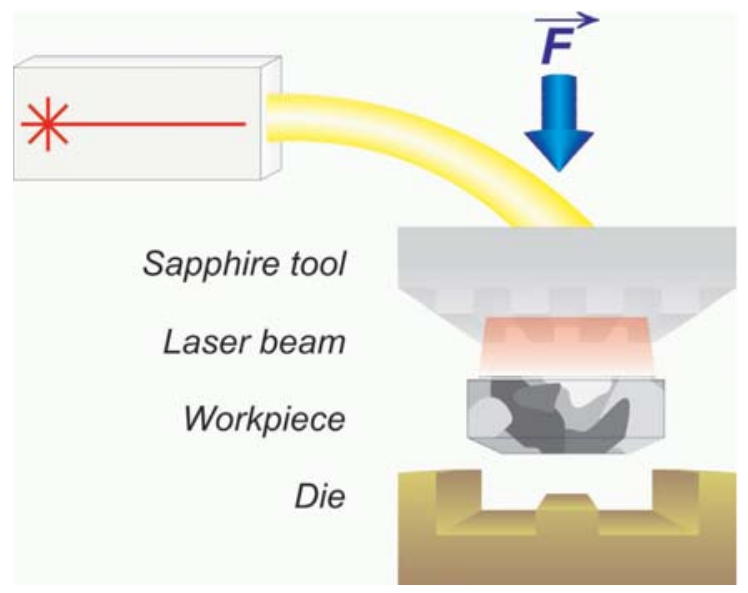

Fig. 14. Principle of laser assisted micro forming

\section{Additive Processes}

Additive processes like rapid prototyping is a group of modern manufacturing technologies that are used to produce three-dimensional prototypes directly from $C A D$ representations. This is achieved by taking discrete twodimensional slices of the three-dimensional CAD file and, either through the deposition of material, the sintering or binding of powder or by selectively changing the state of an ultraviolet (UV) sensitive liquid resin into a solid using a light source, or built up layer-by-layer until the part is complete[27]. According to the raw material used, RP techniques are classified into: Liquid based techniques, Solid based techniques and Powder based techniques.

\section{Liquid based Processes}

Liquid-based RP systems begin with their material in a liquid state. Through a process commonly known as curing, the liquid is converted into a solid state. The important processes under this category are SLA and SGC.

\section{E. Stereolithography (SLA)}

Stereolithography systems build shapes using light to selectively solidify photo-curable resins. Stereolithography creates acrylic or epoxy parts directly from a vat of liquid photo-curable polymer by selectively solidifying the polymer with a scanning laser beam. Parts are built up on an elevator platform that incrementally lowers the part into the vat by the distance of the layer thickness. The schematic of SLA is illustrated in Fig.15. To build each layer, a laser beam is guided across the surface (by servo-controlled galvanometer mirrors, for example) drawing a cross-sectional pattern in the

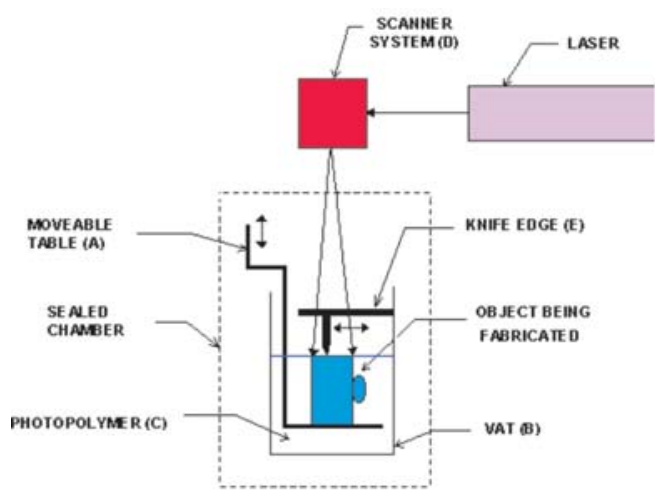

Fig. 15. Principle of Stereolithography

$x-y$ plane to form a solid section. The platform is then lowered into the vat and the next layer is drawn and adhered to the previous layer. These steps are repeated, layer-by-layer, until the complete part is built up.

\section{F. Solid Ground Curing (SGC)}

In SGC, each cross-section is imaged onto an erasable mask plate produced by charging the plate via an ionographic process and then developing the image with an electrostatic toner (like the Xerography process). The schematic of SLA is illustrated in Fig.16. The mask is then 
positioned over a uniform layer of liquid photopolymer, and an intense pulse of UV light is passed through it to selectively cure the material.

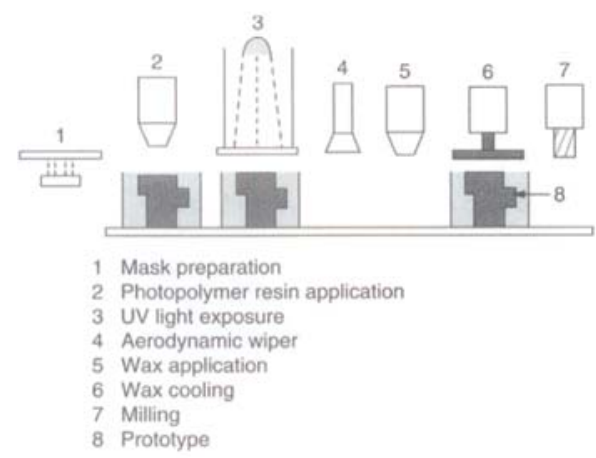

Fig. 16. Principle of Solid Ground Curing

Uncured photopolymer is removed from the layer with a vacuum system and replaced with a low-melting-point, water soluble wax that serves as the sacrificial support. After the wax is cooled, the layer is milled to produce a flat surface. The pattern on the exposed mask is erased by wiping off the toner, and the entire process is repeated. After the part has been completed, the wax is removed by melting.

\section{G. Solid-Based Processes}

The material in these processes can be either in the form of wire, a roll, laminates and pellets. The important processes under this category are FDM and LOM.

\section{H. Fused Deposition Modeling (FDM)}

This approach, called Fused Deposition Modeling, deposits a continuous filament of a thermoplastic polymer or wax through a resistively heated nozzle. Aschematic of FDM is illustrated in Fig.17. The material is delivered as a wire into

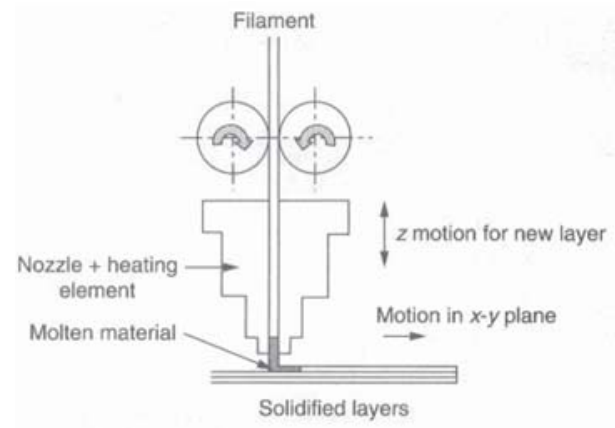

Fig. 17. Principle of Fused deposition modeling the extrusion head and heated to slightly above its flow point so that it solidifies relatively quickly after it exits the nozzle. It is possible to form short overhanging features without the need for explicit support. In general, however, explicit supports are needed. These are drawn out as thin wall sections that can easily be removed upon completion.

\section{Laminated Object Manufacturing (LOM)}

LOM builds shapes with layers of paper or plastic. The principle of LOM is illustrated in Fig. 18. The laminates, which have a thermally activated adhesive, are glued to the previous layer with a heated roller. Alaser cuts the outline of the part cross-section for each layer. The laser then scribes the remaining material in each layer into a cross-hatch pattern of small squares, and as the process repeats, the cross-hatches build up into tiles of support structure. The cross-hatching facilitates removal of this tiled structure when the part is completed.

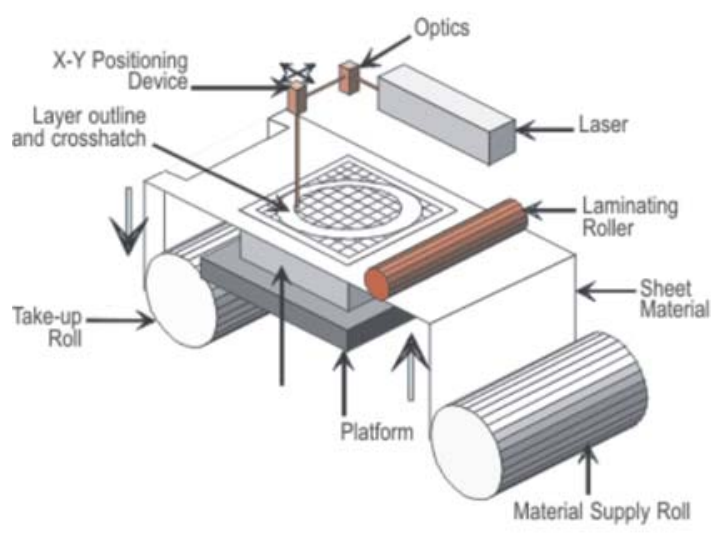

Fig. 18. Principle of Laminated Object Manufacturing

\section{J. Powder-Based Processes}

These processes use powder in grain-like form. Principal amongst these processes are SLS and 3DP.

\section{K. Selective Laser Sintering (SLS)}

As illustrated in Fig. 19, in SLS a layer of powdered material is spread out and leveled over the top surface of the growing structure. A laser then selectively scans the layer to fuse those areas defined by the geometry of the cross-section; the laser energy also fuses layers together. The unfused material remains in place as support structure. After each layer is deposited, an elevator platform lowers the part by the 


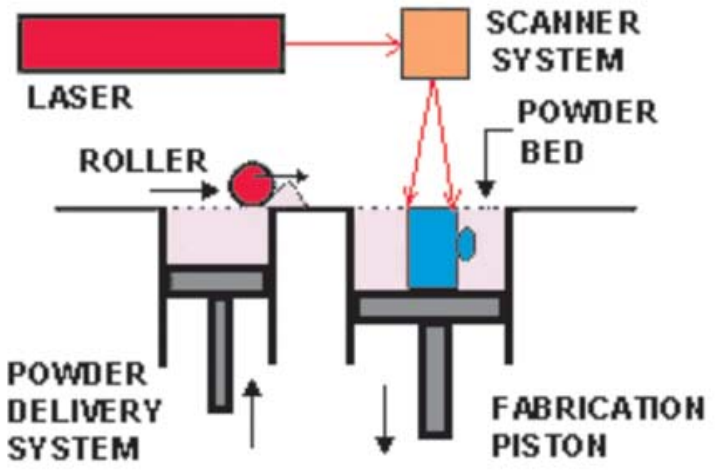

Fig. 19. Principle of Selective Laser Sintering

thickness of the layer, and the next layer of powder is deposited. When the shape is completely built up, the part is separated from the loose supporting powder. Several types of materials are in use, including plastics, waxes, and low melting-temperature metal alloys, as well as polymer coated metals and ceramics for making ${ }^{\circ}$ green ${ }^{\circ}$ performs.

\section{Three Dimensional Printing (3DP)}

It is a hybrid version of selective laser sintering and Ballistic particle manufacturing. The principle of $3 \mathrm{DP}$ is illustrated in Fig. 20. The process starts by depositing a layer of powder object material at the top of a fabrication chamber.

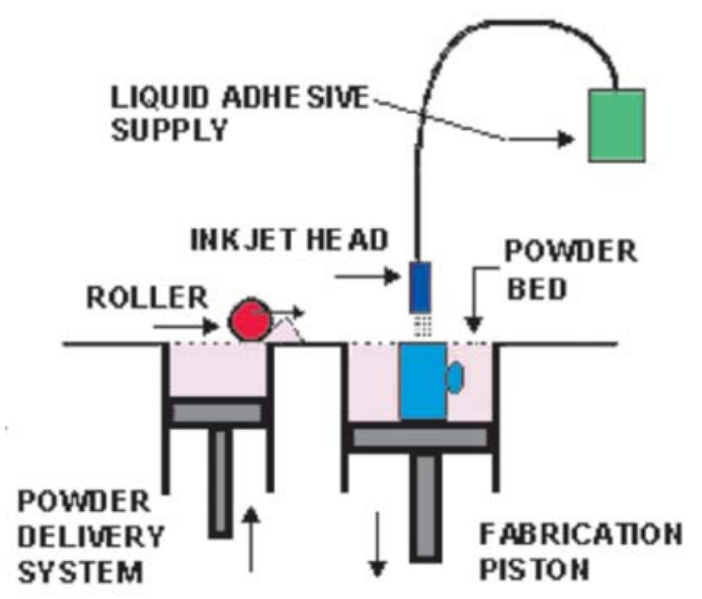

Fig. 20. Principle of Three Dimensional Printing

To accomplish this, a measured quantity of powder is first dispensed from a similar supply chamber by a piston moving upward incrementally. The roller then distributes and compresses the powder at the top of the fabrication chamber. The multi channel jetting head subsequently deposits a liquid adhesive in a two-dimensional pattern onto the layer of the powder, which becomes bonded in the areas where the adhesive is deposited to form a layer of the object. This layer is lowered on completion and process is repeated to form the component.

\section{CONCLUSIONS}

This review provides an overview of modern manufacturing processes and their applications. The modern manufacturing processes in conventional methods like, peel grinding, ductile regime machining and high speed machining, unconventional methods like micro EDM, micro LBM, micro Forming, micro ECM and micro USM, additive processes like rapid prototyping and hybrid processes like combination of electrodischarge and chemical, electrodischarge and ultrasonic etc. Applications include the components used in microelectronic industries, aircraft, biomedical and automobile industries. The expected breakthroughs for future applications of micromanfacturing technology require resolve of some issues like scaling effects, especially in the area of microforming.

\section{REFERENCES}

[1] M.C. Shaw, 1992, Metal Cutting Principles, CBS Publishers \& Distributors, India.

[2] G. Boothroyd and W.A. Knight, 2006, Fundamentals of machining and machine Tools, Taylor \& Francis.

[3] H. Schulz, April 2004, "Why high speed cutting (HSC), Proceedings of the International Conference on high speed machining, China, pp. 1-20.

[4] H.K. f, C. Arendt and R.B. Amor, 2000, "Cutting of hardened steel, Annals of the CIRP, Vol. 49, pp. 547-566.

[5] P.S. Sreejith and B.K.A. Ngoi, 2000, "Material removal mechanisms in precision machining of new materials", International Journal of Machine tools and Manufacture, Vol. 41, pp. 1831-1843.

[6] Robert Aronson, Feb 2006, "Peel grinding", Manufacturing engineering, pp. 57-64,

[7] F.Klocke and A. "aboklicki, 1999, "Laser assisted turning of ceramics", pp. 551-574, In S. Jahamir, M. Ramulu and P. Koshy (eds.), Machining of Ceramics and Composites, Marcel Dekker, Inc. New York.

[8] S. Smith, B. Woddy, J. "iegert and Y. Huang, "Deformation Machining - A New Hybrid Process", Annals of the CIRP, Vol. 56, pp. 281-284, 2007. 
[9] X. Zheng, E. Chen, P. Steele and P. Grothers, 2002, "Shape machining of aerospace composite components using non-traditional abrasive water jet cutting process", Sixth AMST conference, Italy, pp. 507-514.

[10] T. Masuzawa, 2000, State of the art of micromachining, Annals of the CIRP, Vol. 49, pp. 473-485.

[11] K. Egashira and T. Masuzawa,1999, "Micro ultrasonic machining by the application of workpiece vibration", Annals of CIRP, Vol. 48, pp. 131-134.

[12] L. Alting, F. Kimura, H.N. Hansen and G. Bissacco, 2003, "Micro engineering", Annals of CIRP, Vol. 53, pp. 635-658.

[13] M.Kunieda, B.Lauwers, K.P.Rajurkar and B.M.Schumacher, 2005, "Advancing EDM through fundamental insight into the process", Annals of the CIRP, Vol.54, pp. 599-622.

[14] T. Masuzawa, M. Fujino and K. Kobayashi, 1985, Wire electric discharge grinding for micromachining", Annals of the CIRP Vol. 34/1, pp. 431434.

[15] A. Goto, T. Magara, T. Moro, H. Miyake, N. Saito and N. Mohri, 1998, "Formation of hard layer on metallic material by EDM" Proceedings of ISEM, Vol. 12, pp.271-278.

[16] N. Mohri, Y. Fukuzawa, T. Tani and T. Sata, 2002, "Some considerations to machining characteristics of insulating ceramics, Annals of the CIRPVol. 51/1, pp. 161-164.

[17] Avanish Kr. Dubey, Vinod Yadava, 2007, "Experimental study of $\mathrm{Nd}$ :YAG laser beam machining-An overview", Journal of materials processing technology, 2007 in press.
[18] D.T. Pham, S.S. Dimov and P.T. Petkov, 2007, "Laser milling of ceramic components", International Journal of Machine Tools and Manufacture, Vol. 47, pp. 618-626.

[19] HMT, Production Technology, Tata McGraw-Hill publishing company, India.

[20] Hassan El-Hofy, 2005, Advanced machining gprocesses, Nontraditional and Hybrid machining processes, McGraw-Hill, New York.

[21] M. Datta, 1998, IBM Journal of research Develop. Vol. 42/5, pp. 655-669.

[22] M.Kleiner, M.Geiger and A.Klaus, 2003, "Manufacturing of light weight components by metal forming",Annals of CIRP, Vol. 53, pp. 521-542.

[23] J.A.Macgeough, M.C.Leu, K.P.Rajurkar, A.K.M.De Silva and Q.Liu, 2001, "Eletroforming Process and application to micro/Macro Manufacturing", Annals of the CIRP, Vol. 50/2, pp. 499-514.

[24] A.B.M.A. Asad, Takeshi Masaki, M. Rahman, H.S. Lim, Y.S. Wong, 2007, "Tool-based micromachining", Journal of Materials Processing Technology, pp. 204211.

[25] J.P Wulfsberg, S.E. Hilpert, A.Ostendorf and K.Samm, Oct 2003, "Fundamentals of Laserassisted Microforming", 1st Colloquim Processing, Bremen.

[26] M. Geiger, M. Kleiner, R. Eckstein, N. Tiesler and U. Engel: 2001, "Microforming", Annals of the CIRP, Vol. 50/2, pp. 445-462.

[27] R.Hague, I.Campbell and P.Dickens, 2003, "Implications on design of rapid manufacturing", Proc. Instn. Mech. Engrs. Vol.217 Part C: J. Mechanical engineering science, pp.25-30. 